1 Secretaria Municipal de Saúde - Toledo (PR), Brasil mf_leila@hotmail.com

2 Universidade Estadual do Oeste do Paraná (Unioeste), Programa de Pós-Graduação Stricto Sensu em Biociências e Saúde - Cascavel (PR),

Brasil.

neidetm@terra.com.br

3 Universidade Estadual de Londrina (UEL) - Londrina (PR), Brasil.

jtmartins@uel.br

\section{Vivências de ser trabalhador na agroindústria avícola dos usuários da atenção à saúde mental}

\author{
Life experiences as workers in poultry agribusiness of users of mental \\ health care
}

Leila de Fátima Machado ${ }^{\mathbf{1}}$, Neide Tiemi Murofuse $\mathbf{2}$, Julia Trevisan Martins ${ }^{\mathbf{3}}$

RESUMO Neste estudo, propôs-se revelar as percepções de trabalhadores da agroindústria avícola, adoecidos mentalmente, sobre as repercussões do trabalho em sua saúde. Os dados das entrevistas foram agrupados em categorias: a) organização do trabalho na agroindústria avícola, b) mudança física e psicológica no trabalhador, c) uso de drogas psicoativas para suportar o trabalho, d) melhorar o nível escolar para produzir mais, e) medo de ser demitido e falta de reconhecimento, f) convivendo com preconceito da doença mental, g) assédio sexual e moral. Os trabalhadores estão submetidos ao modelo de gestão que associa taylorismo, fordismo e toyotismo, o qual lhes compromete a saúde física e mental.

PALAVRAS-CHAVE Saúde do trabalhador. Doenças profissionais. Saúde mental.

\begin{abstract}
This study aimed at revealing the poultry agribusiness workers' perceptions, who got mentally ill, about the impacts of their work activities. Data obtained during the interviews were grouped into categories as: a) labor organization in the poultry agribusiness, b) worker's physical and psychological changes, c) use of psychoactive drugs to stand the work, d) an opportunity to improve the school level and produce more, e) fear of being fired and the lack of recognition, f) dealing with prejudice of mental illness and g) sexual and moral harassment. Workers are submitted to the management model that associates Taylorism, Fordism and Toyotism, which impairs their physical and mental health.
\end{abstract}

KEYWORDS Occupational health. Occupational diseases. Mental health. 


\section{Introdução}

O modo de produção capitalista tem como meta principal o acúmulo de capital e o lucro. Assim, tanto as condições laborais quanto o processo de organização desse trabalho são direcionados para a produção e obtenção de lucro, sem considerar o bem-estar do homem (ORSO ET AL., 2001). Ao trabalhador, na condição de não proprietário dos meios de produção, cabe vender sua força de trabalho para sobreviver e trabalhar sem o acesso ao produtos e sem controle das condições em que são produzidos. Assim, ele pode viver uma situação conflituosa, pois, se, por um lado, o trabalho pode garantir a sua vida, por outro, pode causar doenças, sofrimentos, sequelas e até mesmo a morte.

Franco, Druck e Seligman-Silva (2010, P. 230), ao analisarem a relação capital/trabalho decorrente das profundas metamorfoses ocorridas no mundo do trabalho, especialmente nas últimas três décadas, denunciam importantes retrocessos sociais que têm disseminado

[...] uma era de precarização social e de trabaIho socialmente desagregador, terreno fértil para o sofrimento e o adoecimento dos indivíduos, configurando o trabalho patogênico.

Os autores complementam dizendo que a atual forma de organização do trabalho tem submetido as pessoas a um ritmo intenso, pressão e intensificação do controle, exigência de cumprimento de metas inalcançáveis, redução do tempo de descanso e pausas, rotatividade no trabalho, entre outros aspectos que têm concorrido para a fragilização dos trabalhadores que, além das perdas de direitos trabalhistas, salariais e da proteção social do trabalho, estão mais vulneráveis a acidentes e a doenças do trabalho.

Estudos mostram que há um aumento no número de pessoas que adoecem e se afastam do trabalho pelos mais variados motivos de saúde (HANDAR, 2012), porém, os de ordem mental e comportamental têm se tornado os mais prevalentes e se configuram entre as maiores causas de afastamento de longo prazo (SELIGMANN-SILVA, 2009). O relatório da IV Conferência Nacional da Saúde do Trabalhador e Trabalhadora revela que os transtornos mentais e comportamentais são a terceira causa mais frequente de afastamentos do trabalho no Brasil, com a previsão de duplicar esse número até 2020 (BRASIL, 2015).

Entre os diversos tipos de atividades, têm-se os desenvolvidos em frigoríficos, em que estudos apontam que além de produzirem agravos e doenças físicas, como, por exemplo, a Lesão por Esforço Repetitivo (LER), podem favorecer a ocorrência do adoecimento mental (MAGRO ET AL., 2014, REMIJO; LARA, 2012, HECK; THOMAZ JÚNIOR, 2012, CÊA; MUROFUSE, 2010). Em pesquisa realizada por Heck e Thomaz Júnior (2012) com trabalhadores da agroindústria avícola, foi identificado que entre os anos de 2006 e 2008 foram concedidos 660 benefícios previdenciários por doenças osteomusculares e transtornos mentais aos trabalhadores de um frigorífico localizado na região Oeste do estado do Paraná, uma média de 220 ao ano.

Sabe-se que existe uma relação entre o trabalho e a doença, porém, ainda predomina a ideia que nega a existência do nexo entre trabalho e saúde mental (PAPARELLI; SATO; OLIVEIRA, 2011), o que, em consequência, leva o trabalhador a ter dificuldades em obter o reconhecimento de que o agravo vivido tem origem ocupacional, seja por parte da empresa ou pelos profissionais da saúde (GLINA ET AL., 2001, SATO; BERNARDO, 2005).

Merlo, Bottega e Perez (2014) afirmam que o trabalhador dificilmente procura um serviço de saúde para falar dos problemas vivenciados no seu trabalho, pois ele tem medo, receio, vergonha, entre outros. Esses autores ainda afirmam que o trabalhador também não é questionado sobre esse aspecto, e, assim, pode haver diluição dos problemas/queixa nas situações pessoais em que a responsabilidade única é da pessoa, 
isto é, a culpa do adoecimento recai sobre o próprio indivíduo.

Diante do exposto, neste estudo, objetivou-se revelar as percepções de trabalhadores da agroindústria avícola, adoecidos mentalmente, sobre as repercussões do trabalho em sua saúde. $\mathrm{O}$ estudo poderá contribuir para a análise das condições em que são realizadas as atividades de trabalho na agroindústria avícola, com base nas experiências e vivências dos trabalhadores, visando à elaboração de ações efetivas para a promoção da saúde, a fim de fortalecer os aspectos positivos do trabalho, diminuindo, assim, os agravos na vida deles.

\section{Metodologia}

Trata-se de um estudo exploratório, descritivo e de abordagem qualitativa. Nesta abordagem, tem-se maior preocupação com a compreensão aprofundada de uma dada realidade por meio da aproximação do pesquisador com os sujeitos nela inseridos (MINAYO, 2008).

Para tanto, utilizou-se o referencial teórico do campo da saúde do trabalhador, o qual concebe o trabalho como organizador da vida social e centraliza nele a determinação social do processo saúde-doença (MENDES; DIAS, 1991). Implica, portanto, a necessidade de olhar para o adoecimento dos trabalhadores a partir das relações destes com o mundo laboral.

Os locais do estudo foram um ambulatório de saúde mental e dois Centros de Atenção Psicossocial (Caps II e Capsad), que prestam assistência às pessoas acometidas por Transtornos Mentais e Comportamentais (TMC) e dependência química, vinculados ao Sistema Único de Saúde (SUS), e que atendem a um município com 119.313 habitantes localizado na região Oeste do estado do Paraná. Destaca-se que essa é uma região com intensa produção avícola, envolvendo aviários, granjeiros, incubatórios, serviços de apoio para descarte de carcaças e cinco unidades industriais frigoríficas.

Os dados foram coletados por meio de entrevista semiestruturada, audiogravadas e transcritas integralmente após autorização dos participantes. O roteiro das entrevistas continha perguntas fechadas, visando à caracterização sociodemográfica, e abertas, com perguntas norteadoras, para investigar as repercussões do trabalho na saúde mental e física dos trabalhadores e a possível relação entre o trabalho e a doença.

Foram estabelecidos como critérios de inclusão: ambos os sexos, estar ou já ter trabalhado em setores da cadeia produtiva da agroindústria avícola e consentir e assinar o Termo de Consentimento Livre e Esclarecido. Foram excluídos os que apresentassem algum tipo de comprometimento para responder aos questionamentos e os menores de 18 anos.

Os possíveis participantes da pesquisa foram identificados por meio dos prontuários de atendimento dos serviços acima mencionados. O número de 14 participantes foi determinado pelo ponto de saturação teórica, isto é, quando ocorreu a repetição das respostas, ou quando as falas dos indivíduos não mais apresentaram algo novo ou diferente do que já havia sido verbalizado (MINAYO, 2008).

As falas dos entrevistados foram submetidas à transcrição, seguidas da leitura e releitura delas. Na sequência, realizou-se a codificação das informações, a qual consistiu em identificar palavras, frases, temas ou conceitos persistentes, destacando-se aqueles referentes ao fenômeno a ser investigado. $\mathrm{Na}$ última fase, procedeu-se à categorização dos códigos que foram preestabelecidos, agrupados em sete categorias, conforme suas similaridades temáticas: a) organização do trabalho na agroindústria avícola, b) mudança física e psicológica no trabalhador, c) usando drogas psicoativas para suportar o trabalho, d) oportunidade de melhorar o nível escolar para produzir mais, e) medo 
de ser demitido e a falta de reconhecimento, f) convivendo com preconceito da doença mental, e g) assédio sexual e moral. A pesquisa foi aprovada pelo Comitê de Ética em Pesquisas com Seres Humanos de acordo com a Resolução no 466/2012 do Conselho Nacional de Saúde, com o parecer número 524.288 de 07/02/2014.

\section{Resultados}

Do total de 14 participantes, sete eram do sexo masculino, com idade entre 29 e 62 anos, e sete do sexo feminino, com idade entre 22 e 44 anos; cinco eram casados, cinco solteiros, três viúvos e um divorciado. No que tange à escolaridade, sete cursaram o ensino médio; dois, o ensino fundamental completo; três não o completaram e um possuía alfabetização funcional. A renda média era de um salário mínimo e meio (o valor do salário mínimo, à época, era de $\mathrm{R} \$ 724,00)$.

Quanto ao diagnóstico, foi identificado, nos prontuários, que todos os participantes tiveram diagnósticos médicos que se enquadravam entre os TMC listados pela Classificação Internacional das Doenças/ CID-10. Entre estes, sete pessoas estavam com doença relacionada ao trabalho, de acordo com Portaria $n^{0} 1.339$, de 18 de novembro de 1999 (BRASIL; OPAS, 2001); três por episódios depressivos e quatro por alcoolismo crônico. Entretanto, nenhum registro nos serviços de saúde atestou relação entre a doença e o trabalho dos entrevistados.

Em relação ao setor de trabalho dos entrevistados, a maioria deles atuava nas áreas industriais dos frigoríficos, nas quais ocorre o processamento dos frangos por meio de esteiras e nóreas em linhas de produção; e na granja e aviário, locais onde há produção de ovos e posterior crescimento e engorda dos pintos que são alojados nos aviários logo após o nascimento, permanecendo até o seu abate por aproximadamente 43 dias. Quanto à função, dez entrevistados exerciam a de operador de produção; três, a de auxiliar de produção; e um, a de apanhador de frango. A atividade era realizada em turnos de 10 horas diárias de trabalho, com frequente realização de horas extras nem sempre remuneradas, mas, computadas como banco de horas. Constatou-se a presença da flexibilização das relações de trabalho por meio de terceirizações, e o tempo de serviço dos entrevistados variou de 18 dias a 24 anos (quadro 1).

Quadro 1. Distribuição dos entrevistados segundo setor de trabalho, função, carga horária, vínculo e tempo de serviço de trabalhadores da agroindústria avícola, Toledo, 2014

\begin{tabular}{|c|c|c|c|c|c|c|c|}
\hline № & Setor & Função & Horário & $\begin{array}{c}\text { Carga horária/ } \\
\text { dia }\end{array}$ & $\begin{array}{l}\text { Hora extra } \\
\text { horas/dia }\end{array}$ & Vínculo & $\begin{array}{c}\text { Tempo de } \\
\text { serviço (anos) }\end{array}$ \\
\hline E1 & Sala de corte; Líder & Aux. Prod. & 05:30 à 16:00 & 10 & Banco de hs & CLT & 1,3 \\
\hline E2 & Sala de corte; Pendura de frango & Op. Prod. & $\begin{array}{l}17: 00 \text { à 03:00 } \\
14: 30 \text { à } 00: 30\end{array}$ & 10 & 0,5 & CLT & 2 \\
\hline E3 & Seladora & Op. Prod. & 16:00 à 02:10 & 10 & 1 & CLT & 9 \\
\hline E4 & Cone; Refile & Op. Prod. & $15: 00$ à $00: 40$ & 10 & 2 & CLT & 2 \\
\hline E5 & Galpões de aviários & $\begin{array}{l}\text { Apanhador } \\
\text { de frango }\end{array}$ & 14:00 à 00:15 & 6 & 2 & $\mathrm{CLT}(6 \mathrm{~m})$ & 15 \\
\hline E6 & $\begin{array}{l}\text { Refeitório; Empanados; Controle de } \\
\text { temperatura }\end{array}$ & Op. Prod. & 02:40 à 12:10 & 10 & 1 & CLT & 14 \\
\hline
\end{tabular}




\begin{tabular}{|c|c|c|c|c|c|c|c|}
\hline \multicolumn{8}{|c|}{ Quadro 1. (cont.) } \\
\hline E7 & Viveiro; Horta; Granja & Op. Prod. & 04:55 à 13:15 & 9 & $\mathrm{NI}$ & CLT & 24 \\
\hline E8 & Desossa & Op. Prod. & 14:00 à 00:15 & 10 & 2 & CLT & 5 \\
\hline E9 & $\begin{array}{l}\text { Higienização; Desossa; Capitão de } \\
\text { equipe }\end{array}$ & Op. Prod. & 21:25 à 04:55 & 7,3 & 1 & CLT & 19 \\
\hline \multirow{2}{*}{ E10 } & Sala de corte; Embalagem (caixas) & Aux. Prod. & 15:15 à 01:01 & 10 & 0,25 & CLT & $0,05(18 d)$ \\
\hline & Entrega de cestas de Natal & $\mathrm{NI}$ & $\mathrm{NI}$ & $\mathrm{NI}$ & $\mathrm{NI}$ & Terc. & 0,25 \\
\hline E11 & Controle de temperatura & Op. Prod. & 15:05 à 00:30 & 10 & 0,5 & CLT & 11 \\
\hline E12 & $\begin{array}{l}\text { Desossa; Higienização; Escaldagem; } \\
\text { Pendura de frangos }\end{array}$ & Op. Prod. & $12: 20$ à $22: 20$ & 10 & 2,5 & CLT & 19 \\
\hline E13 & Sala de corte; Embalagem & Op. Prod. & $14: 20$ à $00: 10$ & 10 & 0,5 & CLT & 1 \\
\hline E14 & $\begin{array}{l}\text { Sala de corte (copa, peito, Kakugiri, } \\
\text { cabeça, classificação, cone); Higie- } \\
\text { nização }\end{array}$ & Op. Prod. & 15:00 à 00:27 & 10 & 1 & CLT & 5,7 \\
\hline
\end{tabular}

Fonte: Banco de dados do pesquisador extraídos das entrevistas realizadas entre março e maio de 2014.

NI: Não informado; Op. Prod.: Operador de Produção; Aux. Prod.: Auxiliar de Produção; CLT: Consolidação das Leis Trabalhistas; Terc.: terceirizado.

Os resultados provenientes dos conteúdos das falas dos entrevistados sobre as suas vivências no trabalho na agroindústria avícola são apresentados nas sete categorias temáticas descritas na sequência.

\section{Categoria 1: Organização do trabalho na agroindústria avícola}

O trabalho realizado pela agroindústria estava organizado de maneira a garantir a produtividade, utilizando, para tanto, $\mathrm{o}$

trabalho em linha, o tempo todo no mesmo local, desossando, era um trabalho cansativo, bastante difícil, forçava os braços e corpo fora de posição, doloroso e muito doentio para as pessoas. (E12).

A empresa contava com pessoas no papel de controlador e vigilante da produção: "tinha operador, tinha capitão que ficava olhando o tempo todo" (E11) para garantir a produtividade e a qualidade dos produtos exigidas pelo mercado de carne internacional, aquela pressão tinha que desossar e dentro daquela qualidade que o cliente deles exigia, aquele tipo exportação que vai pro Japão, sem excesso de pele, sem gordura, sem osso, sem cartilagem. (E11).

O uso da esteira, da nórea e a postura estática do trabalhador garantiam o ritmo e a velocidade da produção: "cada 18 a 20 segundos vinham uma perna e mesmo se você não tinha acabado de desossar uma tinha que pegar outra" (E11). Para o alcance da meta, a empresa estabelecia a quantidade que deveria ser produzida em cada mesa:

tinha tantos funcionário por mesa, aquela mesa teria que produzir no final do mês, da semana ou do dia, a quantidade de perna desossada no caso, pra exportação, se não produzisse ficava aquele acúmulo de produção pra tirar em dia de sábado. (E11).

As falas a seguir ilustram as condições de trabalho às quais estavam submetidos os entrevistados: 
Aquelas esteiras com os espaços e os números, por exemplo: eu tô ali no lugar que é o 10, então todo número 10 que passar a perna é minha. Às vezes a faca nem entrava, não interessa, as pernas continuam descendo, aí ia colocando do lado, então aquelas três que vai vir por minuto, tinha que desossar e ainda tirar as que estão do lado, ao mesmo tempo, quando a faca tava ruim eu não tinha tempo nem de respirar muito menos de conversar. Você depende da faca pra trabalhar, então se a faca estiver ruim, daí ataca os nervos, dá vontade de sair correndo, sofria muito e estressava muito com isso. (E8).

Vou lá no banheiro com 8 minutos, nem vai lá fazer direito e já pensando em retornar, o operador ou o capitão já te dá bronca porque demorou, não podia usar relógio, como é que ia saber o tempo que gastava então, a liberdade era bem pressionada. (E9).

Via que as facas tava mais ruins, ficando velhas, daria pra diminuir um pouco a velocidade, põe lá de 18 segundos põe 20 ou 21 segundos, mas, não, eles queria saber de produzir, não pro lado do funcionário nada, sempre falavam que tem frigorífico que faz até com menos. la no nosso sindicato, passava pra eles o que tava acontecendo e eles marcavam visita lá pra ver, com o Ministério do Trabalho, só que daí era um porém, quando eles marcavam a visita pra ver o nosso lado, lá mudava totalmente, as linhas trabalhava bem mais devagar, as pernas vinha bem mais controladas, as facas parece que já era bem melhor. (E11).

Assim, além do controle do ritmo e da velocidade, e o controle do tempo para a satisfação das necessidades fisiológicas durante o processo de produção, o trabalhador era submetido ao controle do tempo desde a entrada com a troca de roupa:

Depois que passou o crachá ali é cronometrado o tempo, fila pra pegar roupa pra você trabalhar, e é rapidão, se troca, entra. Além de toda a roupa, tinha que pôr a luva de pano pra aquecer, era muito frio, daí as luvas de plástico por cima, e a luva de aço, e aí você tem estar aquele horário lá pra estar na mesa. Não dava pra aguentar ficar dentro dela, calça forrada grossona, blusona de fora também forrada, tinha dias que a temperatura tava muito alta, essa roupa dava um desconforto e touca muito grande ficava caindo no seu olho, me sentia mal, aquela luva de aço apertando a sua mão. (E8).

Ao longo do tempo de serviço dos entrevistados, houve quem testemunhou alterações no mundo do trabalho:

agora mudou tudo, lá na granja mesmo mudou tudo, a ração não pesa mais, tudo automático, aperta o botão lá a ração vai lá em cima na caçamba, pesa, puxa a cordinha, caína caçamba lá. (E7).

Além da automação de equipamentos na agroindústria avícola, também houve mudança nas relações de trabalho:

O serviço terceirizou, foi demitido bastante funcionário com 9 a 10 anos, uns saiu e voltou por terceirizado. O trabalho ia ser o mesmo, só ia ser terceirizado, daí os cara da empreiteira iam tá ganhando esse 300 por funcionário, mas eles iam tá repassado 180 pros funcionários. (E11).

Na época tava com 230 funcionários desossando, na época era 8 mesas, agora tão com 4 porque aumentou o tamanho da mesa, daí diminuiu a quantidade de mesa mas aumentou o tamanho, mas os números de funcionários continua o mesmo. (E11).

\section{Categoria 2: Mudança física e psico- lógica no trabalhador}

A cadência do ritmo de trabalho imposto pela máquina com repetitividade de movimento, posturas inadequadas, exposição a temperaturas altas e baixas, convivência com odores fortes, barulho excessivo, manuseio de instrumentos perfurocortantes, bem como a 
pressão por produtividade característica do modelo de produção adotado no ambiente de trabalho, impactaram significativamente tanto o corpo físico quanto a mente dos trabalhadores, conforme se constata nos depoimentos a seguir:

Eu era de as pessoas fazer o que quisesse comigo e eu ficar quietinha, engoli, daí eu comecei a ver que trabalhando lá eu não podia ficar quietinha, e eu comecei a reagir, daí no dia que ele chegou lá e só não me chamou de santa, eu já cheguei na sala dele e ele já foi me excomungando, eu respondi ele, então ele pegou birra de mim, então quanto mais ele pudesse me judiar mais ele fazia. (E8).

Eu era um cara forte fisicamente, estava num dos melhores momentos da vida, gostava de fazer música, eu era karateca, quase 7 anos de karate, tinha planos de entrar no campeonato paranaense de luta e estava me vendo aleijado e não admitia nunca perder a função que eu tinha no braço todo... retorna e tem que trabalhar, seja com um braço só quebrado, mesmo com dificuldade. Eu fui enfraquecendo psicologicamente, mas a gente precisava trabalhar, filhos menores, sem uma profissão, então, aguentei, mas percebi que eu já não tava mais dando conta de mim, tava desequilibrado, enfraquecido, fui pedir socorro médico e fui me tratar. (E12).

A desconstrução de sonhos iniciais resultou em pesadelo ao trabalhador entrevistado: "Era meu sonho entrar no Frigorífico B, hoje é um pesadelo tá lá dentro" (E14); "Ali éo inferno!" (E11).

\section{Categoria 3: Uso de drogas psicoati- vas para suportar o trabalho}

O uso de substâncias psicoativas no labor servia para atender às altas demandas relacionadas com a rapidez e com a precisão do trabalho nos aviários, e não apenas a uma esfera particular de uso para obtenção de prazer, é o que mostram as falas:
Eu usava cocaína, álcool e maconha durante o trabalho porque me deixava mais enérgico, mais ágil, não sentia preguiça para nada. O que eu tinha que fazer eu fazia com mais rapidez e era para acabar quanto mais rápido o serviço. Fora do trabalho eu usava para descontrair, por prazer. (E5).

Eu comprava de vez em quando uma cerveja, ou se tinha uma caipirinha na geladeira, eu chegava em casa e tomava um copinho, a noite eu chegava cansada, estressada, e tinha acontecido alguma coisa eu tomava, e eu acho que eu fui colocando na minha cabeça que aquilo me ajudava, e na verdade eu acho que me ajudava, achava que ia acalmar, e realmente acalmava mesmo, sei lá, dava uma relaxadona, você até esquecia. (E8).

Na época que eu não era registrado, levava bebida, uns tinham o hábito da maconha, parece que sentia mais disposto, mais rápido, a maioria tomava e fumava pro serviço render mais, tipo um rebite assim, pra rapaziada ficar mais leve e mais rápido, não por maldade, sem brigar com ninguém mais por causa de você se tornar mais rápido, mais ágil. (E9).

Você sai lá de dentro, ia tomar uma cerveja [...] naquele embalo tomando uma mais e outra a mais, por tudo o que você tinha passado durante a semana, pela aquela raiva que passou e não teve coragem de se abrir com o colega, ou aquele pedido de desculpa que não teve coragem de chegar lá e pedir, acabava gerando uma vontade maior de tomar, dava aquela sensação que parece que se eu tomasse uma a mais ia passar, ia aliviar ou esquecer aquilo ali. (E11).

\section{Categoria 4: Melhorar o nível escolar para produzir mais}

Ao ingressarem no frigorífico, os entrevistados identificam aumento do nível de escolaridade e oportunidades de qualificação. 
Entretanto, isso ocorreu exclusivamente para atender às demandas dos frigoríficos: exigências de acordos nacionais ou internacionais, aumento da produtividade e o lucro. As falas dos entrevistados revelam essa realidade:

Fiz um curso pra ir pra inspeção porque eu tinha reumatismo, mas não me mandaram, lá era um lugar melhor, mais quente. Eu sempre fui um cara trabalhador, eu era capitão de uma equipe, líder de uma equipe, a melhor equipe era a minha. Então, ele (o supervisor) falou não. Esse cara não pode sair daqui, ele tem que desossar junto com eles e fica aí e pronto. Então não adiantou nada o meu curso. (E4).

Comecei a trabalhar eu só tinha a quinta série. Daí chegou uma época que veio a lei do Japão e não podia mais funcionário que não tivesse o primeiro grau; daí a empresa ofereceu o curso lá dentro mesmo. Em um ano eu fiz a sexta, sétima e oitava séries, daí pararam, mas eu não fui promovida a nada acho que era só lei mesmo e para ensinar a gente trabalhar mais. (E9).

Pediram pra estudar, estudei, mas ele trabalha bem na desossa, trabalha bem na limpeza, pra que você vai tirar alguém que faz o serviço aqui. Esse cara que é trabalhador não precisa promover porque ele já é bom, ele tem família pra tratar, então também ele não vai sair daqui, esse aímantém. (E12).

\section{Categoria 5: Medo de ser demitido e a falta de reconhecimento}

Os trabalhadores conviviam com o medo da demissão e se submetiam a trabalhos que causavam prejuízos a sua saúde, e os suportavam porque, em suas percepções, era melhor trabalhar do que estar desempregado. Também vivenciavam a falta de reconhecimento pelo que realizavam, conforme se constata nos depoimentos:
Enquanto tá trabalhando, tá produzindo, tá dando conta de tudo, você é ótimo, mas se um dia já não der conta aí você não vale mais nada, já é descartado e jogado fora igual fosse um copinho pra tomar água; acabou não tem mais serventia, é assim que eles são. A gente nunca é reconhecido. (E2).

O braço doía, mas eu ia lá, pendurar na minha linha de produção, eu nunca reclamei por medo de ser mandada embora a gente tem medo de ficar desempregado. A gente se sente muito mal; parece uma pessoa que não tem valor nenhum para o serviço e para ninguém. Muita gente tem raiva, porque é maltratado quando adoece lá dentro, mas ficam quietos por medo de ser demitido. (E9).

\section{Categoria 6: Convivendo com pre- conceito da doença mental}

A doença mental ainda é revestida de preconceitos pela grande maioria da sociedade e pela própria pessoa doente:

na época que eu fiquei internado, a depressão pra mim era vergonhosa entendeu? As pessoas me chamavam assim, como que é de pessoa que quer ficar só na folga assim, e a gente sabendo que não é aquilo, sabendo que é uma coisa mais forte que você imagina. (E4).

O trabalhador doente é acompanhado pelo estigma dentro do ambiente laboral e sofre discriminação:

Eles (patrões) falam que depois que inventou a depressão ninguém quer trabalhar mais. Esse INSS [Instituo Nacional de Seguro Social] tem que pegar e fazer consulta todo mês, podia ser só de 3 em 3 meses. Daínisso eu pensava, meu Deus, será que ele acha que eu não tô doente. Eu sentia que eu tava passando por fingida. O patrão pegava o papel e fala vai, vai embora vai, vai, dormir. Eu saia magoada, chorando, daí na outra vez eu ia lá levava o papel, ele falava assim, tem que pedir a conta. (E10). 


\section{Categoria 7: Assédio sexual e moral}

De acordo com os relatos dos entrevistados, naquele ambiente laboral tem ocorrido a prática de assédio sexual

Tem gente que chega lá e vai pra frente, eu não fui porque eu não aguentei gente passando a mão na minha 'bunda'? Por isso eu ganhei a conta, o cara passou a mão na minha 'bunda'. (E2).

Do mesmo modo, também ocorre o assédio moral, conforme ilustram os relatos a seguir:

Eles queriam obrigar a gente a fazer hora extra, ficar de pé, no mesmo lugar, trabalhando das duas e pouquinho da tarde até meia noite e pouco. Só parar naquele horário da janta e tinha uns minutos lá que mal dava tempo de ir no banheiro... a gente se sente vigiado até para ir ao banheiro. (E8).

Eu pegava a temperatura do frango e colocava nas planilhas. Levava pra casa, pra passar a limpo o que tava errado, só que tava certo, só que queriam que eu marcasse menos de 4 grau, pra ir lá pro Japão, árabe, faziam eu passar raiva, porque tinha que falar pro outro cara falar que eu marquei errado, mas não era eu, daí eu fui ver que eu tava roubando. 6, 5, 7 até 12 graus positivo eu peguei já, daí tá cozinhando o frango, e tem que estar menos de 4 pra eles vender, daí eles ganhavam dinheiro. (E11).

\section{Discussão}

Os depoimentos dos entrevistados mostraram que a atividade na cadeia produtiva da avicultura caracteriza-se pela extrema divisão do trabalho em diversos setores, associada ao uso da esteira e nórea que determinam a postura e a posição estática do trabalhador, além do ritmo e a intensidade de trabalho necessários para que atinjam as metas de produção estabelecidas pelos proprietários dos meios de produção, desrespeitando os biorritmos das pessoas. Tal divisão do trabalho, com decomposição do processo, em que cada operador executa tarefas parciais, é própria do modo de produção capitalista, com a finalidade de possibilitar maior exploração do trabalhador e maior domínio do capital sobre o processo de trabalho (ALVES, 2011).

Nos diversos elos da cadeia produtiva da agroindústria avícola em que atuaram os entrevistados do presente estudo, a atividade realizada caracterizou-se como sendo repetitiva, manual e simples, que pode ser realizada por jovens, adultos e idosos, sem qualquer requisito relacionado com a idade, sexo ou escolaridade. O baixo nível de escolaridade encontrado entre os participantes da presente pesquisa é semelhante entre trabalhadores do corte de cana, que também é um trabalho com características manuais, que exige rapidez e mecanização e com valores remuneratórios baixos (MACIEL ET AL., 2011). A cadeia produtiva avícola imprime a dinâmica do desenvolvimento capitalista, e a baixa escolaridade é usada para a exploração do trabalhador com remuneração de um salário mínimo na grande maioria das vezes (ARAÚJO; RIBEIRO, 2014).

Como afirma Alves (2011), a adoção de inovações organizacionais tanto das formas de gestão quanto da organização do trabalho vivo são centrais no processo de exploração da força de trabalho. Corroborando os resultados de estudos realizados por Cêa e Murofuse (2010), a vivência dos entrevistados indicou que, ao lado da gestão taylorista/fordista, nas atividades avícolas, estão presentes elementos da gestão toyotista da produção, o que intensifica ainda mais a exploração do trabalhador. Para a estrutura e o modelo organizacional adotada na agroindústria avícola, o trabalhador torna-se mero apêndice da maquinaria e automação, o qual se submete ao ritmo, à velocidade e à intensidade ditada pelas esteiras e nóreas realizando movimentos repetitivos e 
rápidos na execução de tarefas encadeadas e sucessivas para o cumprimento de metas previamente estabelecidas (CÊA; MUROFUSE, 2010). Os depoimentos dos entrevistados indicam que, com a introdução das inovações tecnológicas e a flexibilização das relações de trabalho, ocorreu a mudança no processo laboral tanto pela implementação da automação na alimentação das aves quanto pela demissão do trabalhador, motivada pela terceirização de atividades, e sua recontratação com redução de salário, e o aumento da produção contando com o mesmo quantitativo de trabalhadores.

Os entrevistados referiram que trabalham 10 horas diárias, o que é previsto nas leis brasileiras. No entanto, tal quantitativo de horas é maior ainda a se considerar os seguintes fatores: o tempo gasto no trajeto de ida e volta, visto que todos residiam longe do local de trabalho; o uso de transporte para acessá-lo; o tempo despendido na troca de roupa na entrada e na saída do frigorífico; a distância interna a ser percorrida até chegar ao posto de trabalho. Cabe ressaltar, mais uma vez, que se trata de uma atividade que exige a adoção de posturas estáticas no posto de trabalho, com membros mantidos em posição forçada, realizando atividades repetitivas e intensas, $o$ que se torna altamente desgastante. Assim, a extensão do tempo de trabalho, além de aumentar a exposição do trabalhador aos riscos existentes, também diminui o seu tempo de vida fora do trabalho (MAGRO ET AL., 2014), com consequências em todos os aspectos da vida: no trabalho e nas relações familiares e sociais (CÊA; MUROFUSE, 2008).

O surgimento de problemas de saúde física, após o início das atividades na agroindústria avícola, foi relatado pelos entrevistados do presente estudo, sem que tais problemas tenham sido reconhecidos como doença do trabalho tanto pela parte da empresa e dos colegas quanto pelo INSS. Ao contrário, esses problemas muitas vezes foram tratados como se fossem subterfúgios, invenção, enganação dos trabalhadores a fim de obter benefícios de afastamentos ou aposentadoria.
Tal situação tornava-se mais uma fonte de sofrimento para quem já estava com dores e limitado fisicamente para manter o mesmo ritmo de trabalho. Para Dejours (1994), a organização do trabalho afeta diretamente o funcionamento da mente do trabalhador porque envolve o conteúdo das tarefas, as relações humanas e o desejo do trabalhador, limitando ou estimulando suas ideias e desejos, tornando-se um meio favorável ou não para a sua saúde mental.

O trabalho no frigorífico, quando 'quebra' fisicamente um trabalhador, também o 'desmonta' mentalmente como confirmam as falas dos entrevistados. Ao serem admitidos no trabalho, todos eles tinham preparo físico, otimismo, felicidade, sonhos e animação. A boa condição inicial de saúde física e mental mudou após o ingresso no trabalho, e os entrevistados, em consequência de acidentes de trabalho, vivenciaram mudanças em sua condição física, havendo limitações para a execução de atividades tanto no trabalho quanto na vida pessoal, provocando revolta, angústia, nervosismo e desequilíbrio emocional. Tais resultados corroboram os achados de Cêa e Murofuse (2010, P. 42) ao afirmarem que se trata de "um espaço de produção de pessoas adoecidas e até mesmo inválidas, física e psicologicamente, antes de ser um espaço de produção de alimentos de origem avícola". Por sua vez, Dejours (1994) afirma que há uma conexão entre os problemas psíquicos e somáticos e que no trabalho o sofrimento surge quando não é possível descarregar a energia pulsional, que se acumula no aparelho psíquico e transborda para o corpo. Portanto, se não houver uma interrupção do trabalho ou modificação da organização do trabalho, a fadiga desencadeia as patologias mentais.

Os TMC relacionados com o labor não resultam de fatores isolados, mas de contextos de trabalho em interação com o corpo e o aparato psíquico dos trabalhadores. As atividades laborais podem atingir o corpo das pessoas, produzindo agravos e lesões de 
natureza biológica, mas também as de natureza psíquica, podendo provocar processos psicopatológicos relacionados com as condições inadequadas do trabalho a que estão expostas ao realizá-lo (BRASIL; OPAS, 2001).

O trabalho na agroindústria avícola exaure a saúde física e mental do trabalhador, e retira-lhe a dignidade de trabalhar, mudando substancialmente a sua condição de pessoa saudável para a de doente e inválida, conforme o demonstram os depoimentos analisados. Para resistir e suportar as cargas laborais, os entrevistados recorriam ao sindicato e também lançavam mão do uso de substâncias psicoativas, como forma de suportar as cargas laborais. Esses resultados estão em consonância com Lima (2010) ao afirmar que quando ocorre o uso de substâncias psicoativas nos ambientes laborais, a princípio, pode-se configurar como um recurso para enfrentar as altas exigências do trabalho, porém, com o passar do tempo, seu uso trará novos problemas ao próprio labor, por meio de punições, transferências, rebaixamento de função, imposição de tarefas menos atraentes e até mesmo o isolamento do trabalhador por seus colegas e por si mesmo.

A falta de reconhecimento e o medo de ser demitido foram evidenciados nas falas dos trabalhadores, levando-os a desenvolver atividades mesmo quando acometidos por doenças. Segundo Alves (2011), por medo do desemprego, o trabalhador assalariado permite ser explorado em sua força de trabalho, e, muitas vezes, renuncia até aos seus direitos sociais e trabalhistas, trabalhando mesmo adoecido e desgastado.

O preconceito com a doença mental também foi apontado pelos trabalhadores como uma realidade existente entre os 'patrões' e os colegas de trabalho. Para Salles e Barros (2013), o TMC provoca mudanças, afeta o cotidiano, os relacionamentos e os projetos de vida das pessoas e traz as marcas do preconceito e da discriminação. A maior barreira para o emprego de pessoas acometidas por doença psiquiátrica ainda é o estigma, e, assim, a reinserção social e a recuperação da cidadania das pessoas adoecidas de forma a permitir viver e interagir em sociedade, com opções de trabalho, lazer e afetividade, são os grandes desafios.

A precarização do trabalho é um processo que altera a vida dentro e fora do trabalho, pois é sustentada pela gestão pautada no medo, nas práticas participativas forçadas, na imposição da autoaceleração, mescladas com insegurança, sujeição, competição; da desconfiança e do individualismo que leva à desvalorização e à corrosão de valores; da autoimagem decorrente da desestabilização e da vulnerabilidade (FRANCO; DRUCK; SELIGMANSILVA, 2010).

Ainda foi constatado que os trabalhadores do presente estudo sofrem assédio moral e sexual. Para Franco, Druck e Seligmann-Silva (2010), as formas de ataque deliberado contra a dignidade de outra pessoa têm como finalidade submeter o trabalhador às imposições da produtividade e/ou provocar a demissão, esta última principalmente de grupos 'descartáveis' ou indesejados. Ademais, o prolongamento da situação de assédio, sem os devidos suportes afetivos e sociais, produz a vulnerabilidade da saúde e potencializa os riscos de adoecimento mental.

\section{Conclusão}

A partir da apresentação e discussão dos dados, acredita-se que o presente estudo atingiu os objetivos propostos, pois revelou pontos importantes sobre as percepções dos trabalhadores da agroindústria avícola que adoeceram mentalmente devido às repercussões do trabalho em sua saúde.

Pode-se concluir que as atividades realizadas na cadeia de produção avícola contribuíram para satisfazer a necessidade de sobrevivência, mas, ao mesmo tempo, colaboraram para a desconstrução de sonhos, expectativas e desejos motivados pelas limitações adquiridas em função de acidentes e 
doenças físicas e mentais.

A forma de organização laboral a que estavam submetidos os trabalhadores deste estudo, isto é, o modelo de gestão que associa o taylorismo, o fordismo e o toyotismo, propicia a aceleração e o aumento da produção, gerando lucros. Por outro lado, esse modelo suprime os direitos do trabalhador e contribui, sobremaneira, para a ocorrência de inúmeros casos de acidentes e doenças do trabalho quer seja de ordem física, psíquica ou emocional, tornando-se uma ameaça à saúde de qualquer trabalhador, independentemente do setor de atuação das granjas às linhas de produção. Tal modelo impactou significativamente tanto o corpo físico quanto a mente desses trabalhadores.

O desconforto, o desgaste físico e emocional decorrentes das características das atividades desenvolvidas produziram mudanças significativas na vida dos trabalhadores. Após o adoecimento, eles perceberam a discriminação e preconceitos dos empregadores, colegas e médicos. O desamparo dos adoecidos pelo trabalho também ficou ressaltado tanto pela falta de reconhecimento da relação entre saúde e adoecimento, na condição de usuários do SUS, como foi evidenciado pelos prontuários de atendimento analisados, quanto pela ausência de atuação dos sindicatos acionados pelos trabalhadores quando estes se sentiram prejudicados.

Outra questão constatada foi que, por necessidade econômica, os trabalhadores, mesmo adoecidos e sentindo dores, continuam trabalhando, o que os penaliza e desgasta ainda mais.
Além disso, em seu desempenho laboral, os adoecidos por TMC também sofrem o assédio dos gerentes e colegas de trabalho, e para suportar o desgaste gerado pelo trabalho alguns deles utilizam, como estratégia de defesa, o uso de drogas psicoativas.

Assim sendo, esses resultados permitem inferir que há uma relação evidente entre as doenças, em especial as de natureza mental, e o trabalho na agroindústria avícola, na qual foi realizado o presente estudo.

Por fim, ressalta-se que este artigo, apesar de o cenário ser constituído por apenas um ambulatório de saúde mental e dois centros de atenção psicossocial de um município do Oeste Paranaense, propiciou evidências sobre o adoecimento mental dos trabalhadores da agroindústria avícola, e, assim, poderá ser utilizado em experiências e estudos análogos. Entretanto, considera-se importante que mais pesquisas sejam desenvolvidas com o intuito de revelar as condições de trabalho em outras realidades.

\section{Colaboradores}

Leila de Fátima Machado e Neide Tiemi Murofuse participaram da concepção, delineamento do estudo, análise e interpretação dos resultados, redação e revisão crítica do conteúdo intelectual do manuscrito e aprovação da versão final. Julia Trevisan Martins contribuiu na análise e interpretação dos dados, redação e revisão do conteúdo intelectual do manuscrito e aprovação da versão final. 


\section{Referências}

ALVES, G. Trabalho e subjetividade: o espírito do toyotismo na era do capitalismo manipulatório. São Paulo: Boitempo, 2011.

ARAÚJO, R.; RIBEIRO, A. C. O crescimento da agroindústria avícola e as alterações no trabalho familiar rural. REDD - Revista Espaço de Diálogo e Desconexão, Araraquara, v. 8, n. 2, p. 1-17, jan./jun. 2014.

BRASIL. Ministério da Saúde. Conselho Nacional de Saúde. $4^{\mathrm{a}}$ conferência nacional de saúde do trabalhador e da trabalhadora. Relatório final, Brasília, DF, 2015. Disponível em: <http://renastonline.ensp.fiocruz.br/ sites/default/files/arquivos/recursos/Relatorio_4cnstt final_31072015.pdf >. Acesso em: 16 dez. 2015.

Ministério da Saúde; Organização PanAmericana da Saúde no Brasil (OPAS). Doenças relacionadas ao trabalho: manual de procedimentos para serviços de saúde. Brasília, DF: Ministério da Saúde, 2001. Disponível em: <http://bvsms.saude.gov. $\mathrm{br} /$ bvs/publicacoes/doencas_relacionadas_trabalhol. pdf>. Acesso em: 11 ago. 2016.

CÊA, G. S. S.; MUROFUSE, N. T. Associação dos Portadores de LER (AP-LER) na luta pelos direitos dos trabalhadores de frigoríficos do oeste do Paraná. In: TUMOLO, P. S.; BATISTA, R. L. (Org.). Trabalho, economia e educação: perspectivas do capitalismo global. Maringá: Práxis, 2008, p. 421-436.

Processo de trabalho em frigoríficos e as possibilidades de constituição de novas sociabilidades. In: SOUZA, J. S.; ARAÚJO, R. (Org.). Trabalho, educação e sociabilidade. Maringá: Massoni, 2010, p. 39-66.

DEJOURS, C. A. carga psíquica do trabalho. In: DEJOURS, C. et al. (Org.). Psicodinâmica do trabalho: contribuições da Escola Dejouriana à análise da relação prazer, sofrimento e trabalho. São Paulo: Atlas, 1994.

FRANCO, T.; DRUCK, G.; SELIGMAN-SILVA, E. As novas relações de trabalho, o desgaste mental do trabalhador e os transtornos mentais no trabalho precarizado. Rev. bras. saúde ocup. São Paulo, v. 3335, n. 122, p. 229-248, 2010.

GLINA, D. M. R. et al. Saúde mental e trabalho: uma reflexão sobre o nexo com o trabalho e o diagnóstico, com base na prática. Cad. Saúde Pública, Rio de Janeiro, v. 17, n. 3, p. 607-616, maio/jun. 2001. Disponível em: $<$ http://www.scielo.br/scielo.php?script=sci_arttext \&pid=S0102311X2001000300015\&lng=en\&nrm=iso >. Acesso em: 30 jul. 2013

HANDAR, Z. Agravos à saúde do trabalhador: processo saúde-doença-trabalho. In: CÊA, G. S. S.; MUROFUSE, N. T.; DEITOS, R. A. (Org.). Trabalho, Educação e Saúde: formação permanente de profissionais e usuários da saúde pública. Cascavel: EDUNIOESTE, 2012. (v. 2).

HECK, F. M.; THOMAZ JÚNIOR, A. O trabalho degradado em frigoríficos e o adoecimento mental dos trabalhadores. In: SEMINÁRIO DO TRABALHO: trabalho, educação e políticas sociais do século XXI, 8., 2012. Anais eletrônicos... Marilia: UNESP, 2012. Disponível em: <http://www.estudosdotrabalho.org/ texto/gt6/o_trabalho.pdf $>$. Acesso em: 4 jan. 2016.

LIMA, M. E. A. Dependência química e trabalho: uso funcional e disfuncional de drogas nos contextos laborais. Rev. bras. saúde ocup. São Paulo, v. 35, n. 122, p. 260-268, dez. 2010.

MACIEL, M. R. A. et al. Caracterização sócioeconômica do trabalhador temporário da indústria canavieira em lagoa da prata, Minas Gerais, Brasil. Soc. nat. (Online.), Uberlândia, ano 23, n. 2, p. 335-343, maio/ago. 2011.

MAGRO, M. L. P. D. et al. Intensificação e prolongamento da jornada de trabalho nas indústrias de abate e processamento de carnes e seus impactos na saúde dos trabalhadores. Cadernos de psicologia social do trabalho, São Paulo, v. 17, n. 1, p. 67-83, 2014.

MENDES, R.; DIAS, E. C. Da medicina do trabalho à saúde do trabalhador. Rev. Saúde Pública, São Paulo, v. 25, n. 5, out. 1991. Disponível em: <http://www.scielo. 
br/scielo.php?script=sci_arttext\&pid=S0034891019910 00500003\&lng=pt\&nrm=iso $>$. Acesso em: 1 ago. 2013.

MERLO, A. R. C.; BOTTEGA, C. G.; PEREZ, K. V. (Org.). Atenção ao sofrimento e ao adoecimento psíquico do trabalhador e da trabalhadora: cartilha para profissionais do Sistema Único de Saúde - SUS. Porto Alegre: Evangraf, 2014.

MINAYO, M. C. S. O desafio do conhecimento: pesquisa qualitativa em saúde. 11. ed. São Paulo: Hucitec; Abrasco, 2008.

ORSO, P. J. et al. Reflexões acerca das lesões por esforços repetitivos e a organização do trabalho. Rev. online Bibl. Prof. Joel Martins, Campinas, v. 2, n. 2, p. 47-58, fev. 2001.

PAPARELLI, R.; SATO, L.; OLIVEIRA, F. A saúde mental relacionada ao trabalho e os desafios aos profissionais da saúde. Rev. bras. saúde ocup., São Paulo, v. 36, n. 123, jun. 2011. Disponível em: <http://www. scielo.br/scielo.php?script=sci_arttext\&pid=S0303765 72011000100011\&lng=en\&nrm=iso $>$. Acesso em: 1 ago. 2013
REMIJO, A. P.; LARA, R. A superexploração dos trabalhadores nos frigoríficos. In: SEMINÁRIO DO TRABALHO: trabalho, educação e políticas sociais do século XXI, 8., 2012. Anais eletrônicos... Marília: UNESP, 2012. Disponível em: <http://www. estudosdotrabalho.org/texto/gt5/a_superexploracao. pdf>. Acesso em: 11 fev. 2016.

SALLES, M. M.; BARROS, S. Transformações na atenção em saúde mental e na vida cotidiana de usuários: do hospital psiquiátrico ao Centro de Atenção Psicossocial. Saúde em Debate, Rio de Janeiro, v. 37, n. 97, p. 324-335, abr./jun. 2013.

SATO, L.; BERNARDO, M. H. Saúde mental e trabalho: os problemas que persistem. Ciênc. saúde colet., Rio de Janeiro, v. 10, n. 4, dez. 2005.

SELIGMANN-SILVA, S. E. Saúde mental no trabalho contemporâneo. In: CONGRESSO INTERNACIONAL DE STRESS DA ISMA-BR, 9., 2009, Porto Alegre.

Anais... Porto Alegre: ISMA-BR, 2009.

Recebido para publicação em março de 2016

Versão final em agosto de 2016

Conflito de interesses: inexistente

Suporte financeiro: não houve 